\title{
INGUINAL HERNIA REPAIR IN A PERIPHERAL HOSPITAL
}

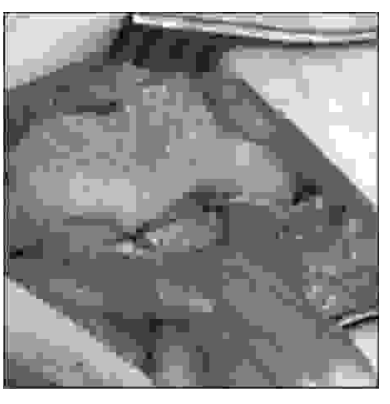

\author{
DR. IFTIKHAR AHMED BHATTI \\ MBBS, MCPS, FCPS \\ Combined Military Hospital, \\ Chunian Cantt
}

\begin{abstract}
Objective: To know the results of two commonly employed surgical procedures i.e., Darning and used of Mesh for inguinal hernia repair in adults, considering the cost effectiveness and better compliance. Design: Case descriptive study. Place and duration of study: Combined Military Hospital, Chunian - Distt Kasur, from November 2004 to April 2006. Patients and Methods: Sixty adult males with the mean age of 48 years had inguinal hernia repair. Only two surgical procedure adopted. Group I includes 10 patients (16.3\%) who had prosthetic Mesh repair. Operative time and hospital stay was almost same in both groups. Results: Out of 60 cases, 38 patients (63\%) had right sided, 19(32\%) had left sided and 03(05\%) had bilateral inguinal hernia. 42(70\%) had indirect hernia, $17(28.3 \%)$ had direct hernia and only 01 patient $(1.7 \%)$ had both types of hernia. In group-1, 04 patients (8\%) had postoperative discomfort in the groin, 02 patients (4\%) had scrotal haematoma and 01 patient $(2 \%)$ had superficial wound sepsis. In Group - II, 01 patients (10\%)had postoperative discomfort and only 01 patient (10\%) had wound sepsis. Not even a single case of recurrence developed in ant of the groups, during the periods of follow up and also no case of chronic residual neuralgia. Conclusion: Based on my study, it is concluded that Darning with prolene is a safe and cost effective procedure than the use of prosthetic mesh.
\end{abstract}

Key words: Inguinal hernia repair, Adults, Peripheral hospital, Darning, Prosthetic mesh.

\section{INTRODUCTION}

Inguinal hernia is among the oldest afflictions of human beings. Over the years, there have been considerable discussions about its various aspects varying from etiology to proper management. A surgeon come across with this problem, in his daily surgical practice quite often and the recurrent hernias are still a persistent challenge even in this modern era of surgery. Hernias occupy a good deal of surgical time and account for about 10 $15 \%$ of all surgical procedures. The majority of these operations (about $80 \%$ ) are performed for inguinal hernia ${ }^{1}$. The true incidence of recurrence after repair is difficult to determine but it usually varies from less than $1 \%$ in special interest centers to as much as $30 \%$ in general surveys. It is generally agreed that by using meticulous technique, principally concentrating on the posterior wall, a recurrence of less than $2 \%$ can be achieved $^{2,3}$.

Over the last many years, prosthetic mesh repair has 
gained popularity due to the excellent results reported by Liechtenstein et $a^{14}$. However mesh repair is an expensive procedure and if mesh repair becomes infected may require removal ${ }^{5}$. The should ice repair also reported low recurrence rate ${ }^{6}$ but it is considered technically challenging, difficult and time consuming. Whereas Darn repair for inguinal hernia originally described by Molony ${ }^{7}$ is quite cheap and easily performed with less operating time and recurrence rate also less than one percent ${ }^{7,8}$. In this repair, the posterior inguinal wall is reinforced by forming a tension - free lattice work with non- absorbable suture material, on which is laid a buttress of fibrous tissue. A good hernia repair should last the patient for the rest of his life, no matter what his age at the time if his primary operation, as Sir Cecil Wakeley said. "A surgeon can do more for the community by operating on hernia case and seeing that his recurrence rate is low, than he can be operating on case of malignant disease" ${ }^{\text {" }}$. The surgeon must bear in mind this responsibility and should aim recurrence not more than $1-2 \%$ for repair of primary inguinal hernia whether indirect or direct. Keeping in view this, the purpose of this study was to determine the results of the commonly employed technique of repair, considering cost-effectiveness, in a peripheral Military hospital where all the facilities of modern surgery are not available and the surrounding population seeking medical advice also belongs to low socioeconomic status. The second objective was to study the post operative complications including wound sepsis, haematoma formation, post operative neuralgia, over and above- the recurrence rate.

\section{PATIENTS AND METHODS}

This study is based on a series of 60 cases of inguinal hernia repair ranging over a period of one and half year, from November 2004 to April 2006. This study has been carried out in Combined Military Hospital Chunian, District Kasur, which is a class - $\mathrm{c}$ military hospital. Males blow the age of 18 years, those having chronic cough with COPD, those having urinary symptoms with Enlarged prostate (as they were referred to Urologist) and those who did nit give consent for operation have been excluded from my series. All the patients were males, ranging in age from18 years to 75 years (means
48 years). The duration of symptomatology varied from 1-12 months in young patients (85\%) whereas $1-3$ years in elderly patients $(15 \%)$. The mode of presentation was usually the appearance of reducible lump in the groin or inguinoscrotal region, with discomfort or pain in the groin. Out of 60 cases, 02 patients $(3.33 \%)$ presented as recurrent hernia, being primarily operated in civil. Patients were evaluated/assessed in outdoor and given appointment for admission or surgery as day case.

Only two surgical repair procedures were employed. These included Darning and prosthetic Mesh repair. Both the procedures were done by me in my study. In Darning, the posterior wall of inguinal canal was strengthened as in Molony's Nylon darn, where a lattice is formed with nylon thread, but in my study Prolene-1 was used. The procedure started with the similar steps as in other hernia repairs. After dealing with the sac the Darn was made. The suture was conducted continuously from the neighborhood of pubic tubercle up to the internal ring and back to the starting points. The suture stated at the medial end by taking a bite of the most medial fibers of the inguinal ligament, where they sweep over the pubic tubercle and catching the fascia on the pubis also. It was continued laterally, taking good bites of the rectus muscle and its sheath to ensure a good darn in the critical medial angle of the repair. When the rectus sheath can no longer be used, the sutures pass onto the conjoined tendon and then in front of and even slightly beyond the internal ring, displacing the cord laterally. The same suture then changes direction and returned medically as the second layer of the Darn. Stitches were introduced at different depths into the inguinal ligament in order that they should not split the inguinal ligament along the lion of sutures. At the medial end, a bite was taken on the inguinal ligament at the pubic tubercle and of the lower end of the rectus sheath and tied. No tension was placed on the sutures in any case. The cord was then laid down on its newly constructed bed and the external oblique aponeurosis, subcutaneous tissue and the skin were sutured in turn. In this way a lattice is formed on which fibrous tissue is laid down on in turn. It was performed in both the varieties of inguinal hernia i.e., direct as well as indirect. 
In the other procedure inguinal canal opened, contents reduced, ligament and trans-fixation of the sac in case of indirect variety and then prolene mash placed with stay sutures. Mostly it was done in very large hernias and recurrent cases, primarily operated elsewhere.

Selection of type of anesthesia was mainly the choice of anesthesiologist. $\ln 70 \%$ general anesthesia was employed, in $22 \%$ spinal anesthesia and only in $8 \%$ local nerve block was used. In $70 \%$ of cases, postoperative pain was relived with injection Dicloran $75 \mathrm{mg} \mathrm{I/M} 12$ hourly for first 24 hours and then oral table on required basis, to avoid breakthrough pain during convalescence. Whereas Spinal or local nerve block case had very good postoperative analgesic effect also. Only three dosage regimen of inject able broad- spectrum antibiotic was used, one injection at the induction of anesthesia and then repeated 08 hourly, followed by oral quinolones for 03 days.

Post operatively patients reported on ${ }^{8 \text { th }}$ day for removal of stitches and examined for early complications if any. They were instructed to avoid exert ional work and lifting heave weight for at least 12 weeks. They were told to have follow up in surgical OPD after 04 weeks for 03 months and then after 06 months and 01 year. The patient who could not come back for follow up, were contacted on telephone.

\section{RESULTS}

Of the 60 patients of my series presented with inguinal hernia, all the patients were males. The peak incidence was found in the $3^{\text {rd }}$ and $4^{\text {th }}$ decades of life. 38 patients $(63 \%)$ had right sided inguinal hernia, $19(32 \%)$ had left sided and $03(05 \%)$ had bilateral inguinal hernia (TableI). Only one side was operated at a time and the other side after a gap of 03 months. 02 patients presented in emergency with sudden appearance of irreducible swelling as obstructed hernia. One has to be operated in emergency, having viable contents and the other treated conservatively and operated on the next operation list.

Based on the operative findings 42 patients (70\%) had indirect variety, $17(28.3 \%)$ had direct and only $01(1.7 \%)$ had both types of hernia (Table-II).

Out of 60 patients, 50 had Darning with Prolene-1 (Group- I) and in 10 cases (Group- II) prosthetic, it was only used in very large hernias (Figure-1), or those who can afford and procure it easily. Darning was even done in obstructed cases. In the recurrent cases, Prolene Darn repair was done in 01 patient, whereas prosthetic mesh was used in the case. Out of 60 cases, 5 patients $(8.33 \%)$ development postoperative urinary retention. It was observed in older age group of patients in whom prostate was found to be within upper normal limits on DRE but they had no urinary symptoms preoperatively. Catheterization was done for 24-48 hours and then they were able to pass urine normally after removal of the catheter.

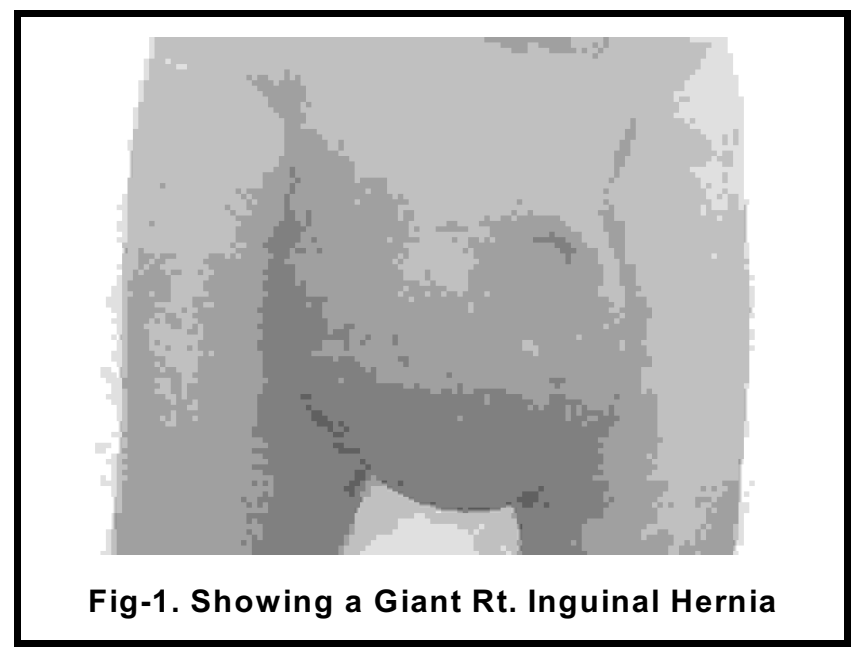

Average hospital stay was 03 days and the majority of the patients were discharged within 05 days. Day case surgery was done in 10 cases (17\%). All the patients had postoperative follow up.

In Group- I, 04 patients (8\%) had postoperative discomfort and mild pain in the groin that persisted for longer than a week and did not require any specific treatment. 02 patients (4\%) had scrotal haematoma and observed in those cases, in which direct sac was quite adherent with the cord and required fine dissection. However it got resolved within few days. 01 patient $(2 \%)$ had superficial wound sepsis, culture sensitivity showed 
staphylococcus aureus, which was treated accordingly.

\begin{tabular}{|l|c|c|}
\hline \multicolumn{3}{|c|}{ Table- I. Showing site of Inguinal Herniation } \\
\hline Site & No of pts & $\%$ age \\
\hline Right & 38 & $63 \%$ \\
\hline Left & 19 & $32 \%$ \\
\hline Bilateral & 03 & $05 \%$ \\
\hline Total & 60 & $100 \%$ \\
\hline
\end{tabular}

\begin{tabular}{|l|c|c|}
\hline \multicolumn{2}{|c|}{ Table-II. Showing different types of Inguinal Hernia under } \\
study
\end{tabular}

Table-III. Showing grouping of patients postoperatively

\begin{tabular}{|l|c|c|c|}
\hline Procedure used & Group & No & $\%$ age \\
\hline Prolene Darn Repair & I & 50 & $83.30 \%$ \\
\hline Prosthetic Mesh repair & II & 10 & $16.70 \%$ \\
\hline Total & - & 60 & $100 \%$ \\
\hline
\end{tabular}

\begin{tabular}{|l|c|c|}
\hline \multicolumn{3}{|c|}{ Table-IV. Showing postoperative complication } \\
\hline Complications observed & $\begin{array}{c}\text { Group-I } \\
(\mathbf{n}=50)\end{array}$ & $\begin{array}{c}\text { Group-II } \\
(\mathbf{n}=10)\end{array}$ \\
\hline Recurrence & None & None \\
\hline $\begin{array}{l}\text { Post operation } \\
\text { Discomfort and pain }\end{array}$ & $4(8 \%)$ & $1(10 \%)$ \\
\hline Scrotal Haematoma & $2(4 \%)$ & None \\
\hline Superficial wound sepsis & $1(2 \%)$ & $1(10 \%)$ \\
\hline
\end{tabular}

In Group-II rate of complications was also comparatively low. 01 patient $(10 \%)$ had postoperative discomfort, no patient had scrotal haematoma, whereas wound sepsis was found in only 01 patient (10\%). Luckily no recurrence was found in both the groups, in the period being followed up. Although the patients have been followed up for a period ranging from 3 - 18 months, but they are still in the process of follow up and with the passage of time, more and more patients will be added.

\section{DISCUSSION}

In inguinal hernia as the basic defect is found to be the weak posterior wall of the inguinal canal and repair of hernia in adults must include restoration of the strength of this layer. It is the detail of technique, the experience and skill of the surgeon that accounts for difference in the final results. In my study more incident found in $3^{\text {rd }}$ and 4 th decades of life and also right sided hernia more common which is comparable to other studies, as done in Islamabad ${ }^{10}$ Hyderabad $^{11}$. Royal Liverpool University Hospital UK ${ }^{12}$.

In my study only two surgical procedures i.e., Prolene Darn and use of prosthetic mesh were employed, with more stress on Darning. In this study two run suturing was done in Darning, but it was ensured a good Darn in the critical medial angle of the repair where recurrences tend to occur. Although in Abrahamson Nylon Darn 8 three run suturing is done but the results are almost the same.

In this study non-absorbable suture material was used and traditionally many surgeons stress the important of non- absorbable suture material, although some feel that absorbable suture for hernia repair, which decay slowly like polydioxanon may be used successfully, ${ }^{13}$ but again it costs more than polypropylene.

In the second procedure where only prolene mesh was used, the result were also very good and comparable to the study carried out at Islamabad ${ }^{10}$, where 100 patients undergone Liechtenstein repair with Gore-tex patch or prolene mesh but the authors themselves recommenced that this procedure to be especially adopted for recurrent hernias and those with sac diameter greater than $8 \mathrm{~cm}$. 
Due to great rush and workload in the Teaching hospital, as well as district level hospital, patients have to wait long for elective surgery of this problem being done by experienced surgeons and most of the time, relatively less experienced doctors ${ }^{14}$ handle these patients completely or partially. So early recurrence hernia repair attributes to poor knowledge of anatomy of the inguinal canal, inadequate dissection, tension on the tissues and surgeon's lack of experience with the repair procedure. ${ }^{15}$ when compared to Liechtenstein repair, Darning has advantage in terms of cot effectiveness as mostly $6 \times 11$ $\mathrm{cm}$ sized mesh is used, which no average costs around fifteen hundred rupees. Darn repair achieves this cost effectiveness without any compromise.

Considering the recurrence rate and other complications, the result of my study are at par with the results of studies carried out in different centers ${ }^{5,16-18}$, and is also in accord with the original study of Molony $^{7}$ and Abrahamson $^{8}$. Even I did not encounter any problem in my patients of Day case surgery ${ }^{19}$.

Laparoscopic inguinal hernia introduced almost a decade ago, with the potential advantages of less operative pain, reduced recovery time and better cosmoses but still it is more expensive, as in the study carried out by Memon and associates $^{20}$ and secondly its availability at peripheral hospitals, due to the budget constraints.

\section{CONCLUSION}

Inguinal hernia, whether primary or recurrent is one of the common problem. The technique used should be simple and once learned, to be performed consistently and effectively. For this purpose, considering the cost effectiveness, safe technique and negligible morbidity, Prolene Darn done meticulously should be the procedure of choice for repair of inguinal hernia in adults, as it has very low recurrence rate which is comparable to any existing procedures.

\section{REFERENCES}

1. Cuschieri SA; Disorder of the abdominal wall. Cuschieri SA, steele RJC, Moosa AR, essential surgical practice. $4^{\text {th }}$ ed. Lonon: Arnold, 2002:167-77.
2. Bennett DH, Kingsnorth AN. Hernia . In: Russell RCG, Williams NS, Bulstrode CJK, (edi). Short practice of surgery. VOL. $2.24^{\text {th }}$ ed. London : Arnold, 2004: 1272-80.

3. Devlin HB. The Abdominal wall and hernias. In: Burnand KG, Young AE,(edi). The new Arid's companions in surgical studies. $3^{\text {rd }} \mathrm{ed}$. London: Churchill Livingston, 1992: 850-64.

4. Lichtenstein I L, Shulman A G, Amid PK. Use of mesh to prevent recurrence of hernias. J Postgrad Med 1990, 87 (1): 155-60.

5. Koukourou A, Lyon W, Rice J, Wattchow A. Prospective randomize trial of polypropylene mesh compared with nylon darn in inguinal hernia repair. Br J Surg 2001; 88:931-4.

6. Kultys J, Pardela M, Drozdz M, Witkowski K, Machelska J. The role of Shouldice's operation in treating inguinal hernia. Wiad Lek; 1997; 50: SU 1 Pt 1: 382-5.

7. Moloney GE. Results of nylon-darn repairs of hernia. Lancet. 1958; 1: 45-8.

8. Abrahamson J. Hernias. In: Maingot's abdominal operations. E11 is H, Schwartz IS. $10^{\text {th }}$ ed. 1997: 479-525.

9. Wakeley CPG, Treatment of certain types of external hernia; Lancet; 1940: 1822-6 (cited by Kirk RM, which inguinal hernia repair? Br Med J; 1983; 287: 4).

10. Zafar IM, Ejaz A, Ghayyur HA, Sikander HK Liechtenstein 's repair. J Surg PIMS; 1993; 5: 18 - 21.

11. Memon AS, Memon AMJ, Ali AS. Management of inguinal hernia repair, experience of 334 cases at Hyderabad. J Coll Physicians Surg Pack 1993; 50-3.

12. Davies N, Thomas M, Mcllroy B, Kingsnorth AN. Early results with the Lichtenstein tension-free hernia repair. Br J Surg 1994; 81: 1478-9.

13. Dick AC, Deans GT, Irwin ST. A prospective study of adult inguinal hernia repairs using absorbable sutures. JR Coll Surg Edinb 1996; 41: 319-20.

14. Miedema BW, Ibrahim SM, Davis BD, Koivunen DG. A prospective trial of primary inguinal repair by surgical trainees. Hernia 2004; 8: 28-32.

15. Wantz GE. Abdominal wall hernias. In :Schwartz SI, Shires GT, Spencer FC Daly JM, Fisher JE, Gallowy AC, (edi). Principles of surgery. Vol. $2.7^{\text {th }}$ ed. New York : Mc 
Graw Hill, 1999: 1585-1611.

16. EL- Barkry AA, Plication darn for the repair of inguinal hernia: a university hospital experience. Saudi Med J 2002; 23: 1347-9.

17. Ali M, Habiba U, Hussain A, Hadi G. The outcome of darning method of inguinal hernia repair using polypropylene in a district hospital. J postgrad Med Inst 2003; 15: 42-5.
18. Farooq O, Rehman BU, Batool Z. Prolene Darn: Safe and effective method for primary inguinal hernia repair. J Coll Physicians Surg Pak 2005; 15: 358-61.

19. Jarrette PEM . Day case surgery. Surgery 1995; 13: 5-7.

20. Memon MA, Fitzgibbons RJ Jr. Assessing risks, coste and benefits of laparoscopic hernia repair. Annu Rev Med 1998; 49:95-109.

\section{Merriment is a} philosophy

not well understood.

It is the sunny side of existence. 